\title{
Chemical recycling of semi-rigid polyurethane foams by using an eco-friendly and green method
}

\author{
Mir Mohammad Alavi Nikje* and Khan Mohammad Tavassoli
}

\begin{tabular}{l}
\hline A R T I C L E I N F O \\
\hline Article history: \\
Received May 30, 2012 \\
Received in Revised form \\
June 23, 2012 \\
Accepted 9 July2012 \\
Available online \\
9 July 2012 \\
\hline Keywords: \\
Glycolysis \\
Polyurethane waste \\
Recycling \\
Integral skin foam \\
Diethylene glycol \\
\hline
\end{tabular}
\begin{abstract}
A B S T R A C T
Degradation of integral skin polyurethane foams (ISPUFs) was performed using diethylene glycol (DEG)/-sorbitol/water ternary green solvent system as an effective polyurethane bond destroying agent in combination with basic catalysts, namely sodium and potassium hydroxides, sodium acetate and sodium carbonate. The effects of studied catalysts were investigated and data showed the high performances of sodium hydroxide in recycling process. After completion of the reactions, appeared split phases contained recycled polyols in the upper phase. Reactions were studied using various DEG/-sorbitol/water ratios and the recovered polyols were characterized and data compared with an authentic sample.
\end{abstract}

(C) 2012 Growing Science Ltd. All rights reserved.

\section{Introduction}

Since the last 40 years, polyurethanes have been used in an ever increasing range of applications e.g. flexible and rigid foams over thermoplastic elastomers to adhesives, paints and varnishes. This wide variety of applications would result in a huge amount of consumption and wastes, causing some environmental problems ${ }^{1}$. In recent years, public awareness of environmental issues has increased enormously, especially awareness of the facts that the world has limited natural resources and a limited capacity to manage the volume of wastes which human activities generate. As polyurethane production volumes increase, the amount of PU waste is also on the rise. By weight, approximately 1.3 Million tons of waste polyurethanes are generated each year only in the US as part of the municipal solid wastes (MSW) representing five percent of all current plastic wastes ${ }^{2}$. Recycling of 
polymeric products has been investigated to enhance the environmental protection and avoid land filling. Traditional and uncontrolled waste destroying methods are not particularly acceptable due to combination of the recycling by pollution of the air and water environments. Because of aforementioned environmental problems, chemical recycling methods proposed in the past three decades. In the recent years and among chemical recycling methods the glycolysis one has been mentioned due to simple process operations as well as economical point of views. This process means using destroying diols and/ or diamines compounds as a solvent system in order to breaking down of polyurethane functional groups and libration of the polyol as well as other valued chemicals. So the glycolysis of waste PUFs into raw materials is one of the principle methods for its recycling ${ }^{3}$. Some studies have revealed that a proper glycolysis process may be used to resolve the disposal problems of PU wastes, along with obtaining a high quality polyol ${ }^{4-7}$. Simioni and his coworkers investigated the effect of different glycols and found ethylene glycol as a suitable solvent allowing the process to be performed in higher polymer / glycol ratios and the product was used as a part of raw materials for RIM of rigid PUF $^{8}$. Gassan has examined polyols recycling from glycolysis of PU and or polyurethane urea ${ }^{9}$. Datta and his co-workers investigated the recycling of PUR foams by using monomeric and polymeric diols and polyols ${ }^{10-13}$. Kanaya and Takahashi reported the decomposition of flexible PUR foam in the presence of alkanol amines without a catalyst at $150{ }^{\circ} \mathrm{C}^{14}$. Our research team has reported some studies on glycol-treated PU foams in the last few years. Integral skin PUF recycling, split-phase development, glycerin-assisted recycling and application of microwave power source for chemical recycling of PUF constitute the main research activities performed in our laboratory ${ }^{15-21}$. In the current work and in the continuing of glycolysis of PUFs waste, an attempt was made to use sorbitol/DEG/water ternary system as a new and eco-friendly solvent-reactant mixture to investigate efficiency in polyol recovering for the first time.

\section{Experimental}

\subsection{Materials and methods}

Polyol (Daltorim ${ }^{\circledR}$ EK 20350) and MDI (Suprasec ${ }^{\circledR}$ 2082) used for polyurethane integral skin foam formulation in 100 and 41 portions and purchased from Huntsman Company. The technical data of Daltorim ${ }^{\circledR}$ EK 20350 and Suprasec ${ }^{\circledR} 2082$ are listed in Tables 1 and 2, respectively. Sorbitol solution (70\%) purchased from Roquette (France). Other chemicals purchased from Merck and used as received without any purification.

FT-IR spectra were recorded by a Bruker Tensor 27 spectrometer (droplet samples were impregnated on $\mathrm{KBr}$ pellets). ${ }^{1} \mathrm{HNMR}$ and ${ }^{13} \mathrm{CNMR}$ spectra were recorded by a Bruker CRX 300 instrument and data were compared with an authentic sample data.

Table 1. Specification of Virgin Polyol (Daltorim ${ }^{\circledR}$ EK 20350)

\begin{tabular}{ccccc}
\hline Appearance & Viscosity, $25^{\circ} \mathrm{C}$ & $\begin{array}{c}\text { Specific gravity, } \\
25^{\circ} \mathrm{C}\end{array}$ & Print point, ${ }^{\circ} \mathrm{C}$ & Burning point, ${ }^{\circ} \mathrm{C}$ \\
\hline Brown liquid & $340 \mathrm{mPas}$ & $1.23 \mathrm{~g} / \mathrm{cm}^{3}$ & 204 & 204 \\
\hline
\end{tabular}

Table 2. Specification of MDI (Suprasec $\left.{ }^{\circledR} 2082\right)$

\begin{tabular}{ccccc}
\hline Appearance & Viscosity & Specific gravity & Flash point & Fire point \\
\hline White viscous liquid & $1740 \mathrm{cps}$ & $1.025 \mathrm{~g} / \mathrm{cm}^{3}$ & $265^{\circ} \mathrm{C}$ & $290^{\circ} \mathrm{C}$ \\
\hline
\end{tabular}

\subsection{Hydroglycolysis of the integral skin foam - General procedure}

The scraps of Integral skin foams (15 g) segmented into small sizes, base catalyst (1\% w/w) and solvent were poured in a three necked flask equipped with a mechanical stirrer and a removable reflux condenser as represented in the table 3 . Heating performed using an oil bath by setting the oil at $195 \pm 5^{\circ} \mathrm{C}$ and the mixture was stirred at $1000 \mathrm{rpm}$. Transesterification reaction carried out at atmospheric pressure and the reaction extends to complete dissolution of the foams. After completion of the reaction, mixture transferred to a 
decanted funnel and was left to be cooled in room temperature. After cooling it was separated into clear brown upper and dark brown lower split phases. The upper layer was recycled polyol and identified by spectroscopy techniques.

Table 3. Effects of the solvent system composition on the split phase ratios

\begin{tabular}{lcccccc}
\hline Sample & $\begin{array}{c}\text { DEG } \\
(\% \mathrm{w} / \mathrm{w})\end{array}$ & $\begin{array}{c}\text { Sorbitol } \\
(\% \mathrm{w} / \mathrm{w})\end{array}$ & $\begin{array}{c}\text { Water } \\
(\% \mathrm{w} / \mathrm{w})\end{array}$ & $\begin{array}{c}\text { Time } \\
(\mathrm{min})\end{array}$ & $\begin{array}{c}\text { Upper phase } \\
(\%)\end{array}$ & $\begin{array}{c}\text { Lower phase } \\
(\%)\end{array}$ \\
\hline GSF1 & 95 & 3.5 & 1.5 & 8 & 42 & 58 \\
\hline GSF2 & 90 & 7.0 & 3.0 & 9 & 50 & 50 \\
GSF3 & 85 & 10.5 & 4.5 & 9 & 50 & 50 \\
GSF4 & 80 & 14.0 & 6.0 & 10 & 54 & 46 \\
GSF5 & 75 & 17.5 & 7.5 & 10 & 58 & 42 \\
\hline
\end{tabular}

\section{Results and Discussion}

\subsection{Recovered polyol characterization}

One of the main goals in this study was using sorbitol as a portion of destroying solvent system in the recycling process. For this propose and in order to studying the effects of sorbitol in the glycolysis reaction, we examined the dependence of reaction times to the sorbitol content by using different basic catalysts. We found out that with the increasing sorbitol content, reaction time increased probably due to increasing viscosity of the reaction media and strong intra and intermolecular $\mathrm{H}$ bonds formations between sorbitol molecules and/ or other hydroxyl content compounds. When the viscosity is increased, the chain motion for nucleophiles attaching of nucleophiles restricted and reaction rate is dropping significantly. In the meantime, in order to examine the role of the base catalyst in the foam dissolution, the first reaction performed on uncatalyzed condition and data showed incompletion of the reaction even at the longer reaction times. This observation reveals the role of the basic catalysts in glycolysis process. In the other words, for complete and adequate foam dissolution, reaction should be catalyzed using appropriate bases. Therefore, different catalysts were examined in combination with solvent system in order to decreasing the dissolution time. To overcoming of the viscosity increasing of the media, solvent system was held as DEG (95\%wt), sorbitol $(3.5 \% \mathrm{wt})$ and water $(1.5 \% \mathrm{wt})$ in combination with various catalysts in $1 \mathrm{pbw}$ ratios. Results showed the perfect dissolution of the foam at adequate reaction times in the presence of studied bases, but $\mathrm{NaOH}$ had significant effect in decreasing of the dissolution times. All data collected in the Table 4.

Table 4. Dissolution time of ISPUFs by different catalysts

\begin{tabular}{cccccc} 
Catalyst & $\mathrm{NaOH}$ & $\mathrm{KOH}$ & $\mathrm{NaOAc}$ & $\mathrm{K}_{2} \mathrm{CO}_{3}$ \\
\hline Dissolution time (min) & 8 & 9 & 11 & 9 \\
\hline
\end{tabular}

Another goal in this study was the reduction of consumed energy by avoiding of mass losses and several tests were performed to finding the best reaction temperature using $\mathrm{NaOH}$ as a catalyst. The best reaction temperature was found in the range of $200-205^{\circ} \mathrm{C}$. Results for adjusting of the reaction parameters are shown in the Table 5 .

Table 5. Dissolution studies of ISPUF in different temperatures

\begin{tabular}{lcclcl}
\hline Solution no. & PUF $(\mathrm{g})$ & Solvent $(\mathrm{g})$ & Temperature $\left({ }^{\circ} \mathrm{C}\right)$ & Time $(\mathrm{min})$ & Result \\
\hline 1 & 15 & 15 & $150 \pm 5$ & 20 & Foam not dissolved \\
2 & 15 & 15 & $180 \pm 5$ & 20 & Foam dissolved within 14 min \\
3 & 15 & 15 & $190 \pm 5$ & 20 & Foam dissolved within 8 min. \\
4 & 15 & 15 & $205 \pm 5$ & 20 & Excellent dissolution with solvent evaporation \\
\hline
\end{tabular}

\subsection{Reaction scheme}

Schemes 1 and 2 show the reaction mechanism of the polyurethane bond break down by DEG and sorbitol anions as the effective nucleophiles, respectively. 


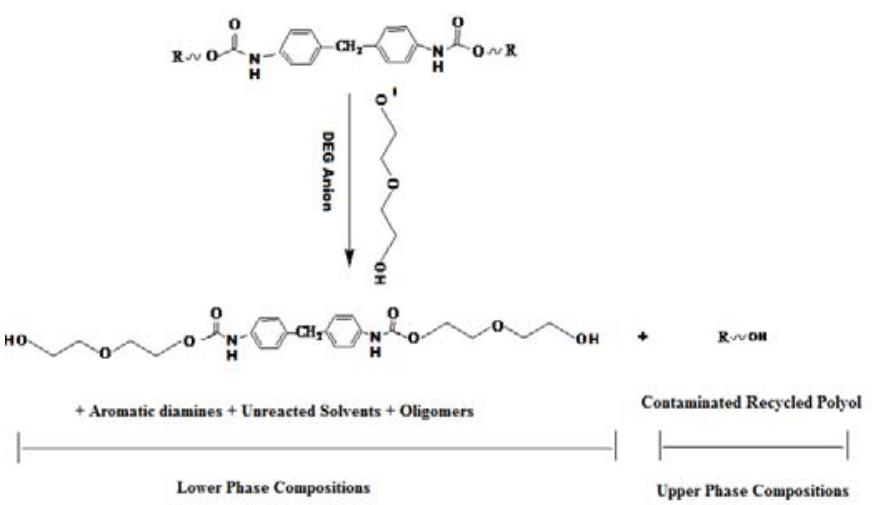

Scheme 1: PU bond cleavage by DEG anio

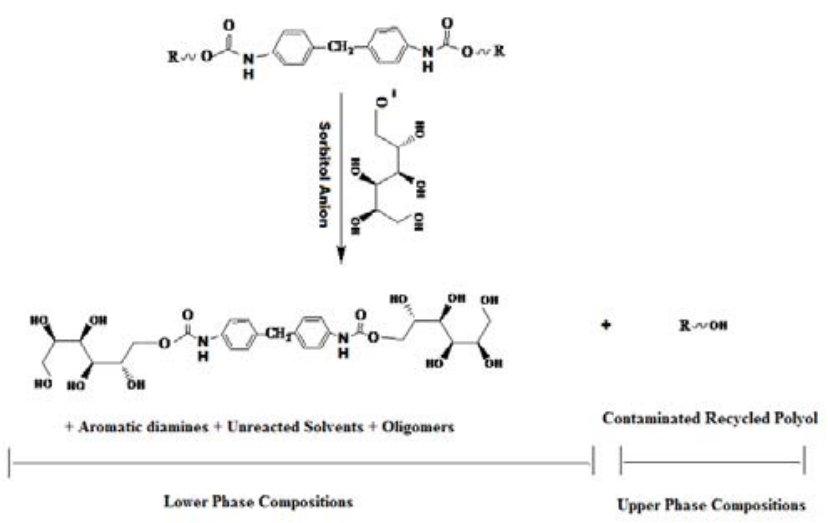

Scheme 2: PU bond cleavage using sorbitol anion

As shown in the schemes, the first step is the conversion of the DEG and sorbitol molecules to the corresponding anions and further attaching of the anions to the PU functional groups. The results of the PU bond breaking is libration of the polyol as a value material in combination with other functionalized chemicals.

\subsection{Structural elucidation of recycled polyol using spectroscopy methods}

${ }^{1}$ HNMR spectra of virgin and recycled polyols are shown in the figure 1 . The peak in the region $1.1 \mathrm{ppm}$ is corresponding to methyl equivalent hydrogen's and the peaks in the $3.0-4.0 \mathrm{ppm}$ regions are relative to hydrogen's located in the $\beta$ position to the oxygen atoms. The comparison of ${ }^{1}$ HNMR spectra of virgin polyol and recycled product in the upper phase represents that chemical structures of the compared compounds are too similar, except the peaks in the region about 6.6-7.1 ppm and 6.9-7.2 ppm which is showed in figure 2 (b) which are related to the aromatic ring hydrogens which remained as aromatic diamines and contaminate the upper phase.

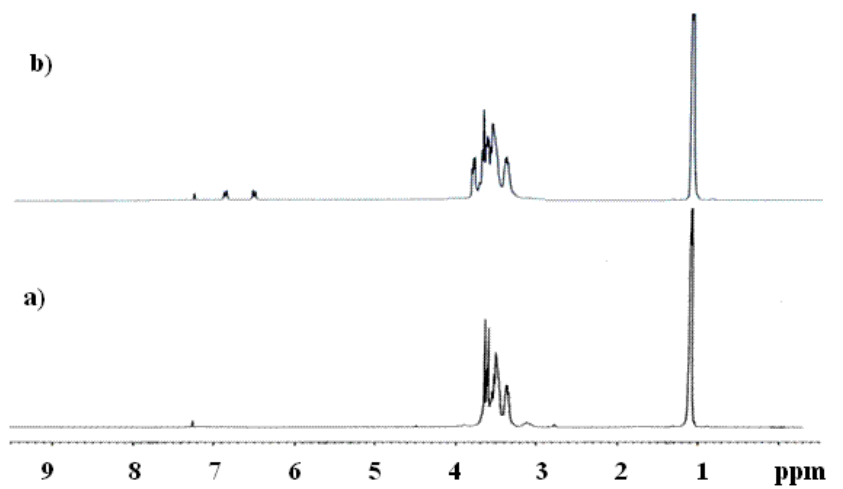

Fig. 1. ${ }^{1} \mathrm{HNMR}$ spectra of virgin (a) and recycled (b) polyols

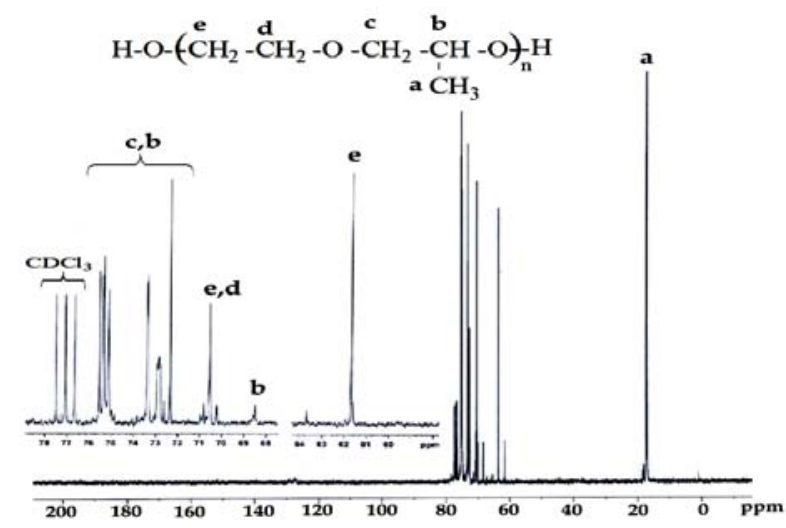

Fig. 3. ${ }^{13} \mathrm{CNMR}$ spectrum of integral skin virgin polyol

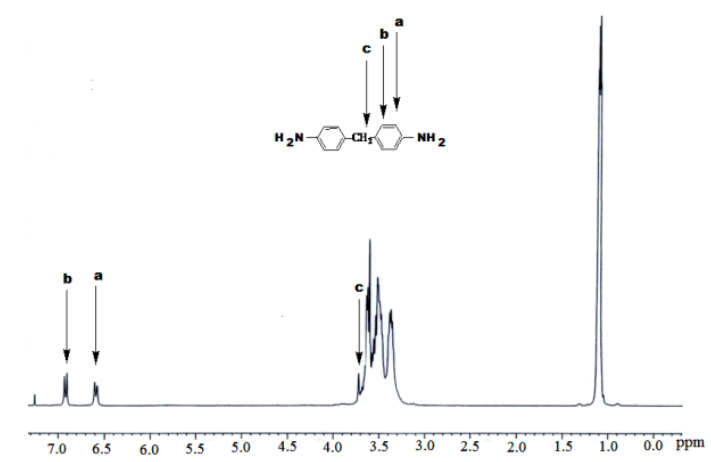

Fig. 2. ${ }^{1} \mathrm{HNMR}$ spectrum of contaminated polyols by aromatic diamine

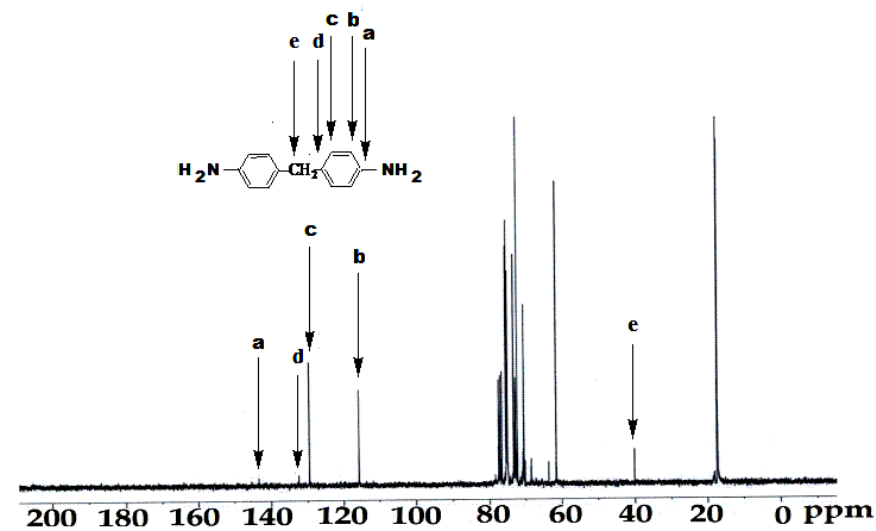

Fig. 4. ${ }^{13} \mathrm{CNMR}$ spectrum of contaminated integral skin recycled polyols 
The ${ }^{13}$ CNMR spectra of recycled polyols at different conditions were quite similar to virgin polyol except 5 new peaks at 40,114.5, 130.5, 129 and $146 \mathrm{ppm}$ are caused by aromatic diamines compounds that slightly had been dissolved in the upper phase. (Fig. 3, Fig. 4 and Fig. 5).

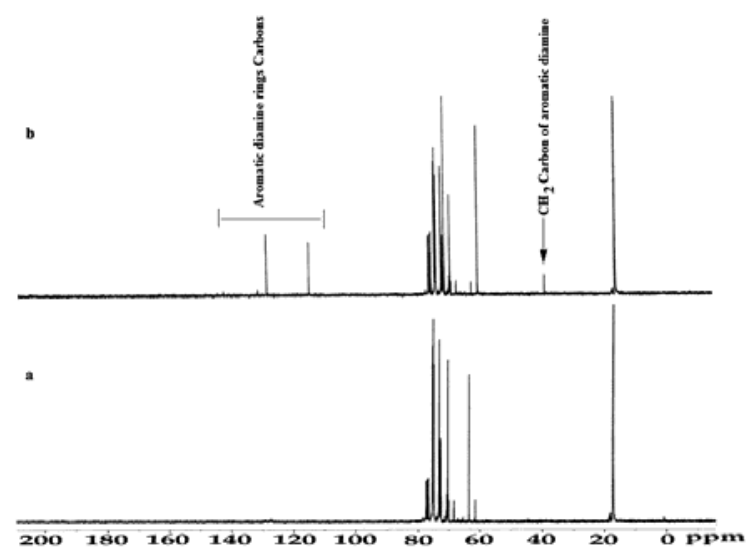

Fig. 5. ${ }^{13} \mathrm{CNMR}$ spectra of virgin (a) and contaminated recycled (b) polyols

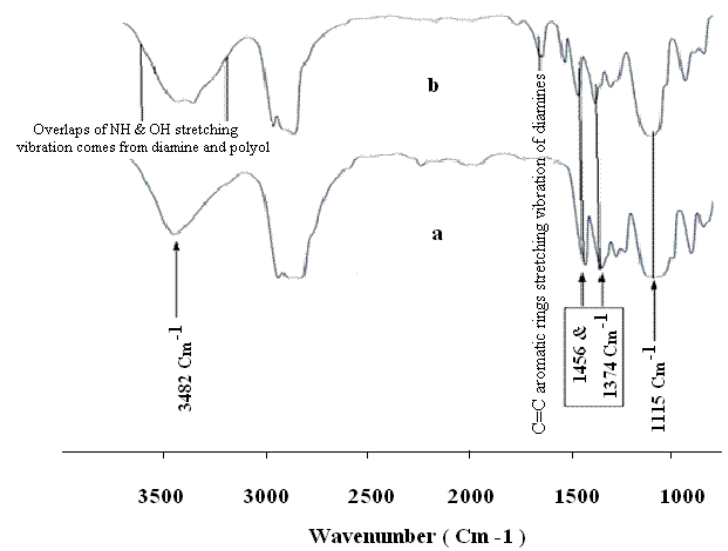

Fig. 6. FTIR spectra of virgin (a) and amine contaminated recycled (b) polyols

FTIR spectroscoy was another method in order to confirmation of successful recycling process and contamination of the recyclate by aromatic diamines. Figure 6 shows the FTIR spectrum of contaminated recyclate. In the FTIR spectrum, the absorption band at $1115 \mathrm{~cm}^{-1}$ related to aliphatic ether group of polyether polyol. Bending vibrations of methylene groups appear in the polyol chain at 1374 and $1456 \mathrm{~cm}^{-1}$, stretching vibrations of $\mathrm{CH}$ bonds in aliphatic carbons are found at 2970-2868 $\mathrm{cm}^{-1}$ and stretching vibrations of $\mathrm{OH}$ groups are found at $3482 \mathrm{~cm}^{-1}$. The expected results from FTIR spectra are similar to NMR spectra results and some additional signals are appeared due to presence of aromatic diamines contaminants in combination with respected signals to virgin polyol.

\subsection{Proposed mechanisms of PU bonds degradations}

There are two mechanistic alternatives for formation of aromatic diamines. The first mechanism is the reaction of the water with $\mathrm{NCO}$ groups and formation of unstable intermediate carbamic acid, which results in elimination of $\mathrm{CO}_{2}$ and formation of aromatic diamines. The second mechanism is $\mathrm{C}-\mathrm{N}$ bond cleavage mechanism which results in an unstable carbonate and aromatic amine. The proposed mechanisms are shown in the Scheme 3.

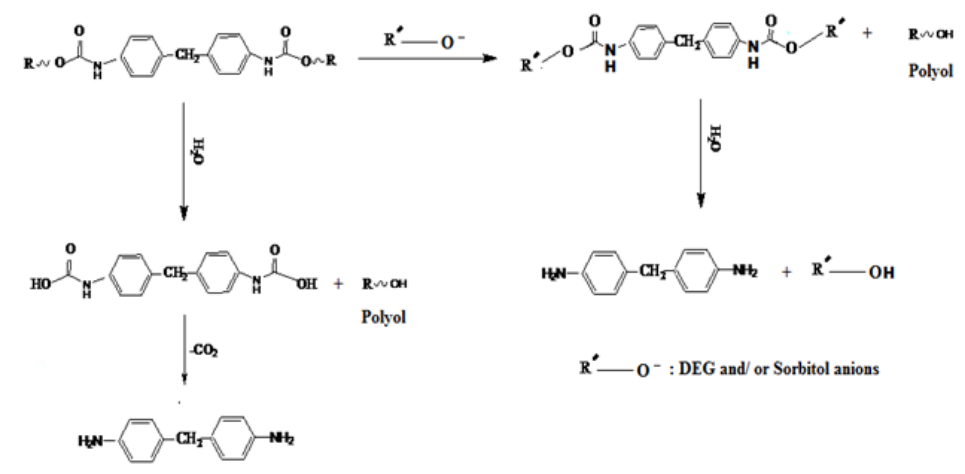

Scheme 3: Reaction scheme for aromatic diamine formation

\section{Conclusions}

Hydroglycolysis of ISPUFs has been carried out at atmospheric pressure using DEG /sorbitol/ water mixtures as destroying solvent system and $\mathrm{NaOH}$ as the catalyst, respectively. By increasing the sorbitol concentration in the solvent system, the prolonged reaction times were absorved. This phenomenen is related to increasing in the viscosity of the media and preventing the nucleophilic 
attaching of the DEG and/ or sorbitol anions to the urethane functional groups. The reported process is eco-friendly one and can be added in the PUFs wastes recycling as a versatile and convenient process.

\section{Acknowledgements}

The authors thank Imam Khomeini International University (IKIU) for the financial supporting of Dr. Alavi Nikje with grant number of 751575-1391.

\section{References}

1. Report (2002) New forecasts for polypropylene polystyrene and polyurethane, Gobi International. www.gobi.co.uk.

2. Report (2008) published on Rooftherm Polyurethane Green Technologies Company. www.roofthem.co.uk.

3. Hopper J. F. G., Parrinello G., Parfondry A., Kroesen K.W. (1992) Recent Developments in the Chemical Recycling of Flexible Polyurethanes. In: Utech 92 Conference, The Hague, the Netherlands.Mar 31-Apr 2.

4. Scheirs J. (1998) Polymer recycling: Science, technology and applications. John Wiley \& Sons Ltd, England.

5. Hopper J. F. G., Parrinello G., Parfondry A., Kroesen K. W. (1992) Recent developments in the chemical recycling of flexible polyurethanes. Cell Polym., 11, 388-396.

6. Hicks D.A., Krommenhoek M., Sonderbery D. J., Hopper J. F. G. (1994) Polyurethanes recycling and waste management. Cell Polym., 13, 259 -276

7. Van Der Wal H. R. (1994). New Chemical Recycling Process for Polyurethanes. J. Reinf. Plast. Comp., 13, 87 -96.

8. Simioni F., Modesti M. (1993) Glycolysis of flexible polyurethane foams. Cell Polym., 12, 337 -348.

9. Gassan M., Naber B., Neiss V., Moeckel P., Weissflog W. (1994) Preparation of recyclatepolyols and the use thereof in the preparation of polyurethanes. US Patent 5357006.

10. Datta J., Pasternak S. (2005) Oligourethane glycols obtained in glycolysis of polyurethane foam as semifinished products for cast urethane elastomers preparation. Polimery, 50, 352-357.

11. Datta J., Rohn M. (2007) Glycolysis of polyurethane wastes. Part I. Glycolysis agents and catalysts. Polimery, 52, 579 -582.

12. Datta J., Rohn M. (2007) Glycolysis of polyurethane wastes. Part II. Purification and use of glycolysis products. Polimery, 52, 627-633.

13. Datta J., Pasternak S. (2008) Syntheses and properties of polyurethanes got from glycolysis products obtained from waste polyurethane foams. Polimery, 53, 27-32.

14. Molero C., Lucas A. D., Rodriguez J. F. (2006) Recovery of polyols from flexible polyurethane foam by "split-phase" glycolysis with new catalysts. Polym Degrad Stabil., 91, 894 -901.

15. Alavi Nikje M. M., Haghshenas M., Bagheri Garmarudi A. (2006) Glycolysis of waste polyurethane integral skin foams from steering wheel. Polym Plast Technol ., 45, 569-573.

16. Alavi Nikje M. M., Haghshenas M., Bagheri Garmarudi A. (2006) Preparation and application of glycolysed polyurethane integral skin foams recyclate from automotive wastes. Polym Bull., 56, 257-265.

17. Alavi Nikje M. M., Haghshenas M., Bagheri Garmarudi A. (2007) Split-phase "glycolysis of flexible PUF wastes and application of recovered phases in rigid and flexible foams production. Polym Plast Technol., 46, 265-271.

18. Alavi Nikje M. M., Nikrah M., Haghshenas M. (2007) Glycerin as a new glycolysing agent for chemical recycling of cold cure polyurethane foam wastes in "split-phase" condition. Polym Bull., 58, 411-423.

19. Alavi Nikje, M. M., Nikrah, M. (2007) Microwave assisted glycolysis of polyurethane cold cure foam wastes from automotive seats in "split-phase" condition. Polym Plast Technol., 46, 409-415.

20. Alavi Nikje, M. M., Nikrah, M. (2007) Chemical recycling and liquefaction of rigid polyurethane foam wastes through microwave assisted glycolysis process. J Macromol Sci A., 44, 613-617.

21. Alavi Nikje, M. M., Nikrah, M., Haghshenas, M. (2007) Microwave assisted "split-phase" glycolysis of polyurethane flexible foam wastes. Polym Bull., 59, 91-104.

22. Alavi Nikje, M. M., Haji Agha Mohammadi, F. (2008) Microwave-assisted PU bond cleavage via hydroglycolysis process at atmospheric pressure. J. Cell Plast., 44, 367-380.

23. Alavi Nikje, M. M., Bagheri Garmarudi, A. (2010) Regeneration of polyol by pentaerythritol-assisted glycolysis of flexible polyurethane foam wastes. Iran Polym J., 19, 287 -295. 